речья // Самарский научный вестник. 2014. № 2(8). C. $35-53$.

8. Васильева И.Н., Выборнов А.А. Некоторые аспекты изучения неолита Марийского Поволжья // Археология и этнография Марийского края. Вопросы археологии эпохи камня и бронзы в Среднем Поволжье и Волго-Камье. Вып. 41. Йошкар-Ола: МарНИИЯЛИ. 2015. С. 68-98.

9. Васильева И.Н., Выборнов А.А. Время появления и динамика распространения неолитических керамических традиций в Поволжье // Поволжская археология. 2016. № 3 (17). С. 1-20.

10. Белановская Т.Д. Из древнейшего прошлого Нижнего Подонья: Поселение времени неолита и энеолита Ракушечный Яр. СПб.: Изд-во С.-Петербургского ун-та, 1995. 199 с.

11. Бобринский А.А., Васильева И.Н. О некоторых особенностях пластического сырья в истории гончарства // Проблемы древней истории Северного Прикаспия. Самара: Изд-во СамГПУ, 1998. С. 193-217.

12. Васильева И.Н. О выделении видов исходного пластичного сырья древнейшей керамики и их ареалах в эпоху неолита (по материалам Поволжья) // Современные подходы к изучению древней керамики в археологии. М.: Изд-во ИА РАН, 2015. С. 16-23.

13. Мазуркевич А.Н., Долбунова Е.В., Кулькова М.А. Керамические традиции в раннем неолите Восточной Европы // Российский археологический ежегодник. 2013. № 3. С. 27-109.

14. Васильева И.Н., Салугина Н.П. Лоскутный налеп // Древнее гончарство. Итоги и перспективы изучения. М.: Изд-во ИА РАН. 2010. С. 72-87.
15. Васильева И.Н., Салугина Н.П. Опыт применения зонального лоскутного налепа в реконструкции способов изготовления крупных сосудов эпохи неолита // Самарский научный вестник. 2015. № 3 (12). C. 29-36.

16. Смольянинов Р.В., Сурков А.В. Ранний неолит Верхнего Дона // Самарский научный вестник. 2014. № 3 (8). С. 161-170.

17. Сурков А.В. Неолитические памятники Среднего Похоперья. Воронеж: Изд-во ВГПУ, 2007. $121 \mathrm{c.}$

18. Спатаро М. Характеристики технологии производства керамики раннего неолита России // Caмарский научный вестник. 2015. № 3 (12). С. 142153.

19. Васильева И.Н., Выборнов А.А. Очаги/центры ранненеолитического гончарства в европейской части России // Традиции и инновации в изучении древнейшей керамики: мат-лы междунар. науч. конф., 24-27 мая 2016 года. СПб.: Изд-во ИИМК РАН, 2016. C. $45-48$.

20. Васильева И.Н. Сравнительное изучение технологии керамики «елшанского облика» Волго-Уралья и сопредельных регионов // Культурные процессы в Циркумбалтийском пространстве в раннем и среднем голоцене: докл. междунар. науч. конф., посвящ. 70-летию со дня рождения В.И. Тимофеева. Санкт-Петербург, 26-28 апреля 2017 г. СПб.: МАЭ PAH, 2017. C. 231-234.

Работа выполнена при поддержке РГНФ: проeкm № 16-11-63015.

\title{
POTTERY TECHNOLOGY OF THE EARLY NEOLITHIC POPULATION PODON'YA
}

\section{(C) 2017}

Vasilyeva Irina Nikolaevna, candidate of historical sciences, senior researcher of Research Department Samara State University of Social Sciences and Education (Samara, Russian Federation)

Abstract. The paper publishes the long-term study results of the Early Neolithic population pottery technology in the Lower, Middle and Upper Don Region. This research was carried out within the framework of the historical and cultural approach by the method of A.A. Bobrinsky. It was based on binocular microscopy, traceology and experiment in the form of physical modeling. 483 samples of ceramics (conditionally separate vessels) were subjected to techno-technological analysis. They originate from the cultural layers of the Rakushechny Yar camp (294) and I Razdorskaya site (4), located in the Lower Don region, as well as 14 sites of the Middle and Upper Don Region containing Karamyshev type ceramics (185). The authors give a general description of the Early Neolithic pottery of the Don region and a comparative analysis of the data on pottery technology of the Lower, Middle and Upper Don Region population. The problems of the origin and distribution of early Neolithic pottery traditions are considered, the similarities and differences in the neolithization process in the Don region and the Volga region are distinguished.

Keywords: Don; Early Neolithic; neolithization; Rakushechny Yar culture; Karamyshev culture; ceramics; pottery technology; binocular microscopy; traceology; experiment; origin of pottery; cultural traditions; culturogenesis.

УДК 902

Статья поступила в редакцию 07.07.2017

\section{ДРЕВНОСТИ КОНЦА VI - ПЕРВОЙ ПОЛОВИНЫ V ТЫС. ДО Н.Э. В ВЕРХНЕМ ПОДВИНЬИ} (C) 2017

\footnotetext{
Мазуркевич Андрей Николаевич, старший научный сотрудник, главный хранитель отдела археологии Восточной Европы и Сибири Долбунова Екатерина Владимировна, кандидат исторических наук, младший научный сотрудник отдела археологии Восточной Европы и Сибири Государственный Эрмитаж (г. Санкт-Петербург, Российская Федерация)
}

Аннотащия. Выделенная в конце 1980-х годов руднянская культура А.М. Микляевым и А.Н. Мазуркевичем рассматривалась авторами как самостоятельное культурное явление. В последнее время было открыто большое количество новых памятников с материалами, которые можно отнести к руднянской культуре 
Мазуркевич А.Н., Долбунова Е.В.

Древности конца VI - первой половины V тыс. до н.э. в Верхнем Подвиньи $\quad 07.00 .00$ - исторические науки и археология

(п. Сертея II, XIV, XXXIV и др.). Стало возможно проследить пространственное и ландшафтное распределение памятников. Новые материалы в значительной степени дополняют характеристику материальной культуры, в первую очередь, керамики, относящейся к фазам «d» и «е», домостроительства. Также появились новые радиоуглеродные датировки для руднянской культуры, уточняющие ее хронологию, позволяющие датировать период ее бытования с конца VI тыс. до сер. V тыс. до н.э. Наиболее близкие аналогии как керамическому комплексу, так и предметам из кости и рога мы находим в материалах нижнего течения р. Западная Двина в Лубанской котловине, откуда и мог исходить культурный импульс, приведший к появлению на рассматриваемой территории руднянской археологической культуры. Аналогии руднянской культуре указывают на смену векторов культурных взаимодействий в конце 6 тыс. до н.э., что является маркером разрушения сложившейся сети культурных связей, существовавшей до этого на протяжении 7-6 тыс. до н.э.

Ключевые слова: неолит; неолитизация; ранний неолит; лесная зона Восточной Европы; Верхнее Подвинье; нарвская культура; руднянская культура; культура Эртебелле; памятники типа Струмель; технология керамики; радиоуглеродная хронология; культурные традиции.

Руднянская археологическая культура была выделена по материалам стратифицированной стоянки Рудня Сертейская, раскопанной в сертейском археологическом микрорегионе (Велижский р-н Смоленской обл.) в 1983-1987 гг. [1; 2]. На основании радиоуглеродных датировок было определено время существования этих древностей в последней четверти VI тыс. до н.э. - начале V тыс. до н.э. [3]. Данная культурная традиция не является на данной территории древнейшей/первой, в отличие от Восточной Прибалтики. Этот культурный цикл следует за более ранними неолитическими, в том числе керамическими, традициями [4].

За прошедшее время с конца 1980-х годов были выявлены памятники с материалами, которые можно отнести к руднянской культуре. Новые материалы в значительной степени дополняют характеристику материальной культуры, в первую очередь, глиняной посуды, а также домостроительства. На основе анализа керамического комплекса можно предположить существование нескольких групп керамики, которые относятся к выделенным ранее фазам «d», «е» и «d$1 »[2]$.

Первоначально материалы керамической фазы «d» были определены по фрагментам сосудов, найденным в культурном слое $B$ стоянки Рудня Сертейская, по имени которой эта культура и получила свое название. Культурный слой $B$ приурочен к нижнему отделу синеватого сапропеля, который сильно опесчанен и насыщен мелкими угольками (рис. 1) [1; 2, c. 7, рис. 2]. В нем было найдено около 30 сосудов, разница в технологии, морфологии и орнаментации между которыми теперь, после увеличения источниковедческой базы, позволяет нам выделить две отдельные группы сосудов, относящихся к фазам «d» и $« d-1 »$.

Керамика фазы «d» (тип 2 по [2]) выполнена из теста со значительной примесью раковины и органики (визуальные определения) (рис. 2). Сосуды слеплены из растянутых лент/лоскутов (крайняя фрагментарность сосудов не позволяет точно определить вид первоначальных элементов) с «S» креплением, укладывавшихся по кругу. Толщина сосудов 0,40,7 см. С обеих сторон видны следы расчесов зубчатым орудием. Некоторые сосуды имели лощение внешней поверхности. Они имеют очень плохую сохранность. Сосуды, плохо обожжённые, подвергались лишь температурной сушке при невысоких температурах, судя по заключению специалистов
НИИ фарфора (соответствующее заключение см. [2]). Из-за плохой сохранности сложно понять, как часто использовалась техника выбивки стенки сосудов. Венчики уплощенные, сосуды с незначительной профилировкой (CS-вида). Имеется шиповидное дно. Эти сосуды орнаментировались ямками, насечками, мелкими наколами, не похожими на существовавшие до этого, и оттисками тонкого изогнутого гребенчатого штампа. Орнамент состоит из одного или нескольких горизонтальных или сочетания горизонтальных и вертикальных рядов, образованных, как правило, посредством одного из приемов. Только два сосуда имели орнаментальную композицию из сочетания двух приемов: ямок и насечек, ямок и оттисков гребенчатого штампа. Орнамент располагался только в верхней трети сосуда, остальная часть некоторых покрыта расчесами, которые создавали своеобразную эстетику данного типа посуды. Сильная фрагментарность материала не позволяет восстановить декор всего сосуда, но имеющиеся в коллекции отдельные фрагменты придонных частей и тулова с орнаментом позволяют предположить сложный декор с орнаментом на различных частях сосуда и свободными зонами между этими участками. Исключение представляет один сосуд, орнаментированный треугольными оттисками, составленными в горизонтальные ряды, который также отличает и способ лепки - он слеплен из лент $\mathrm{N}$-крепления, незначительно растянутых, укладывавшихся по кругу. К этой же группе нужно отнести серию небольших мисочек (тип 3 в статье [2]), без орнамента, С-формы профиля, с приостренными венчиками.

Керамика фазы «d-1» (тип 1 в статье [2]) выполнена из плотного теста с примесью раковины и органики (визуальные определения) (рис. 3-4). Сосуды сделаны из значительно растянутых лент N-крепления. На обеих сторонах фиксируются следы «расчесов», большая часть внешней стороны сосудов в дальнейшем подвергалась также лощению. Использовалась выбивка сосудов. На поверхности сосудов хорошо видна сетка растрескивания от высыхания глины, которая подвергалась лишь температурной сушке. Венчики - скошенные вовнутрь, уплощенные, прямые или наклонные вовнутрь. Днища округлые, иногда с шиповидным окончанием. Толщина сосудов 0,7-0,9 см. Горшки не орнаментированные или орнаментированные одним рядом ямок под венчиком, также сетка из «расчесов» могла служить своеобразным украшением сосудов. 


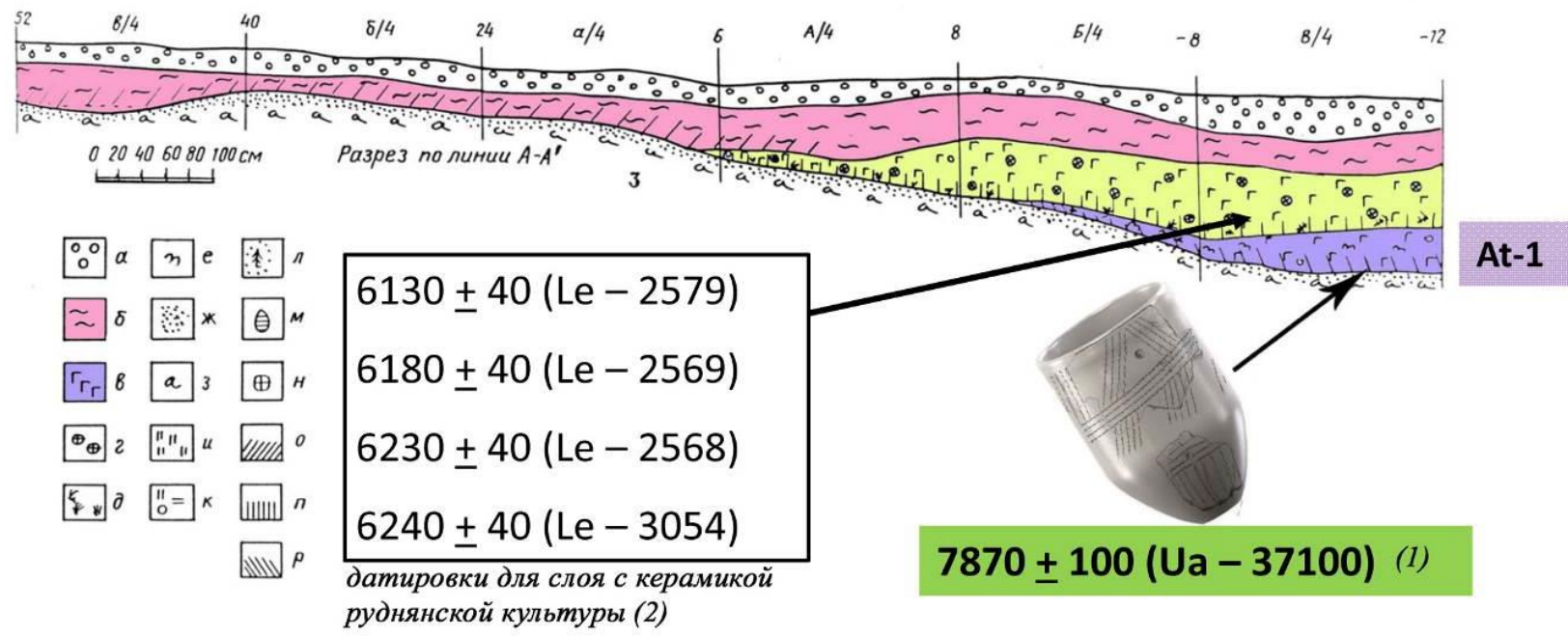

Рисунок 1 - Стратиграфия стоянки Рудня Сертейская [согласно 2] с указанием датировок, полученных из слоев, вмещающих материалы ранненеолитической сертейской культуры (фаза «а») (1) и руднянской культуры (2)
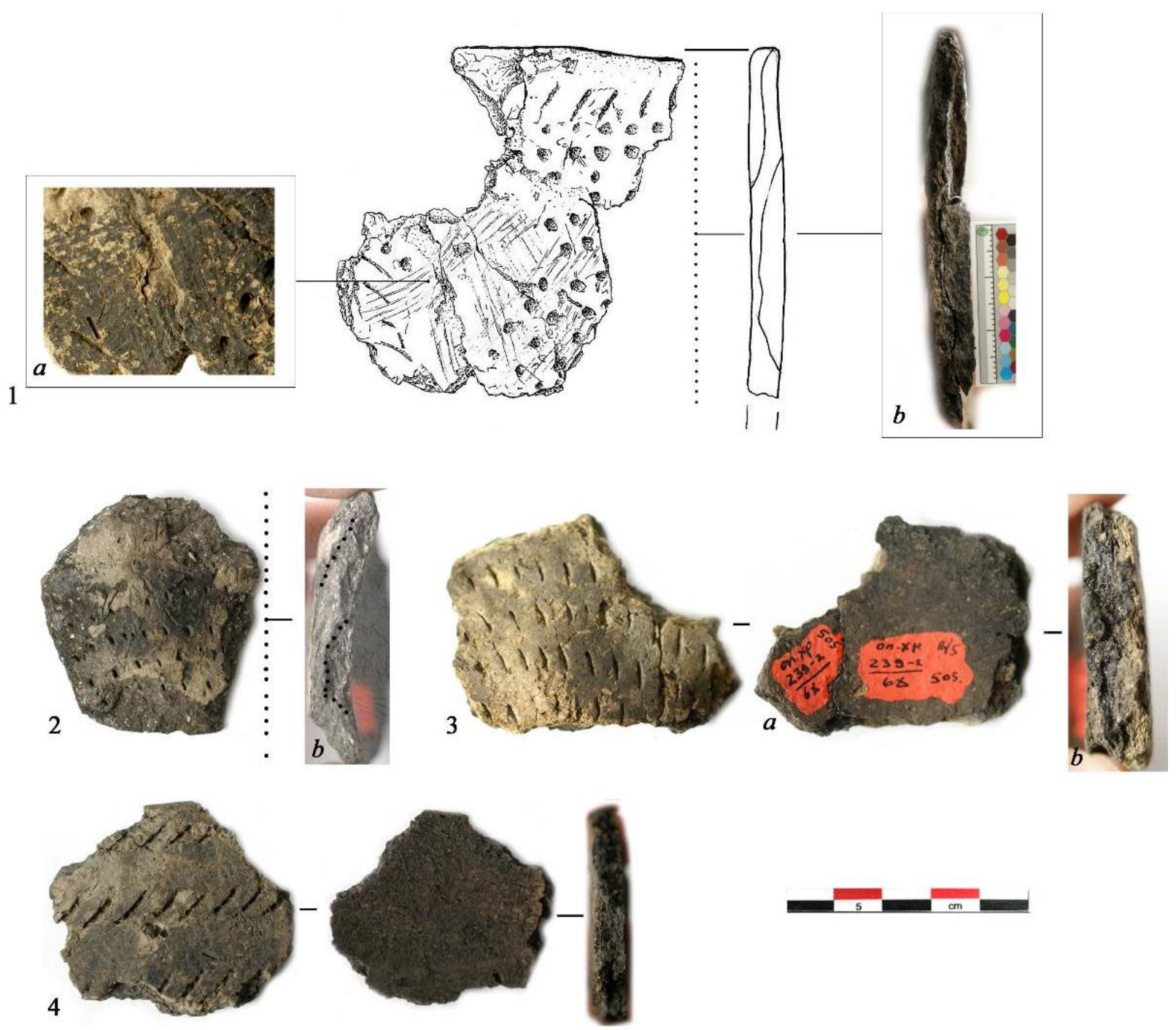

Рисунок 2 - Фрагменты глиняных сосудов фазы «d» (п. Рудня Сертейская) с указанием следов, оставленных при обработке поверхности $(1 a, 3 a)$, и видов крепления лент/лоскутов $(1 b, 2 b, 3 b)$

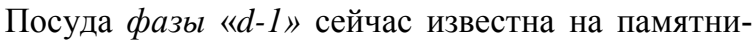
ках Сертея II-2, X, XIV, XXXIV, где она была найдена в торфяниковых отложениях. Также немногочисленные фрагменты, относящиеся к фазе «d-1», были найдены в песчаных отложениях п. Узмень, Усвяты II. Возможно, к этому культурному срезу относятся остатки различных объектов на п. Сертея XIV, X. Единственной чертой сходства между сосудами, относящимися к этим двум фазам, является формовочная масса с примесью раковины и органики. Пространственный анализ показывает их залегание в одном слое, но на различных участках памятника (см. [2]). 

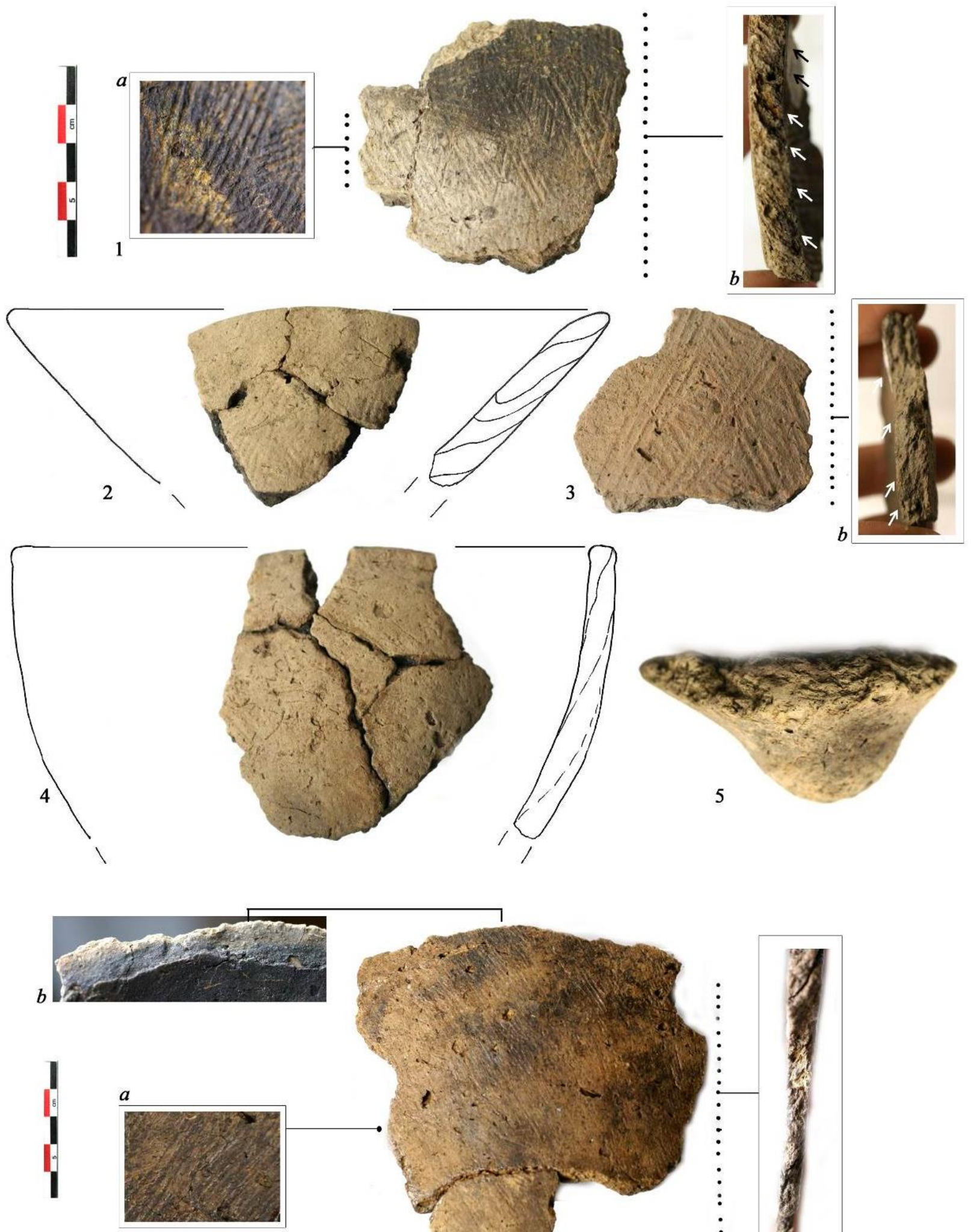

6

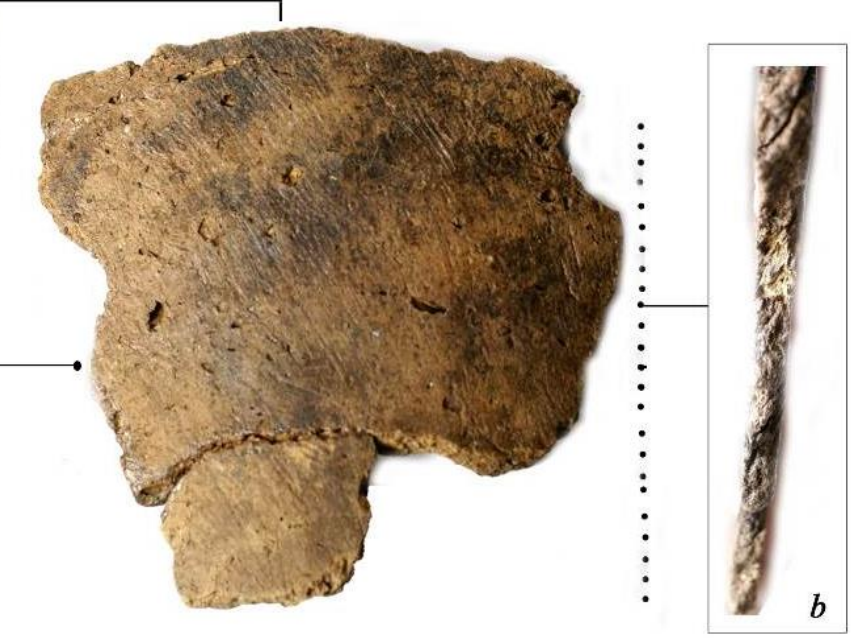

Рисунок 3 - Фрагменты глиняных сосудов фазы «d-1»

(1-2, 4, 6- п. Сертея XIV; 3- п. Усвяты II; 5- п. Рудня Сертейская)

с указанием следов, оставленных при обработке поверхности $(1 a, 6 a)$, и мест стыковки лент $(1 b, 3 b, 6 b)$

Материалы фазы «е» рассматривались как продолжение развития фазы «d» на более позднем хронологическом этапе [2]. Они были найдены на суходолах в песчаных отложениях памятников Узмень, Усвяты II, Сертея II $\alpha$. Сосуды сделаны из жирного теста с примесью органики (визуальные определения) из лент/лоскутов с S-креплением (рис. 5). Поверхность сосудов заглажена, изредка встречаются следы расчесов, скрытых в ходе последующих операций обработки сосудов. Венчики сосудов уплощенные, прямые. Керамика орнаментирована мелкими точечными наколами, сеткой из прочерченных линий, небольшими оттисками овальной формы. 

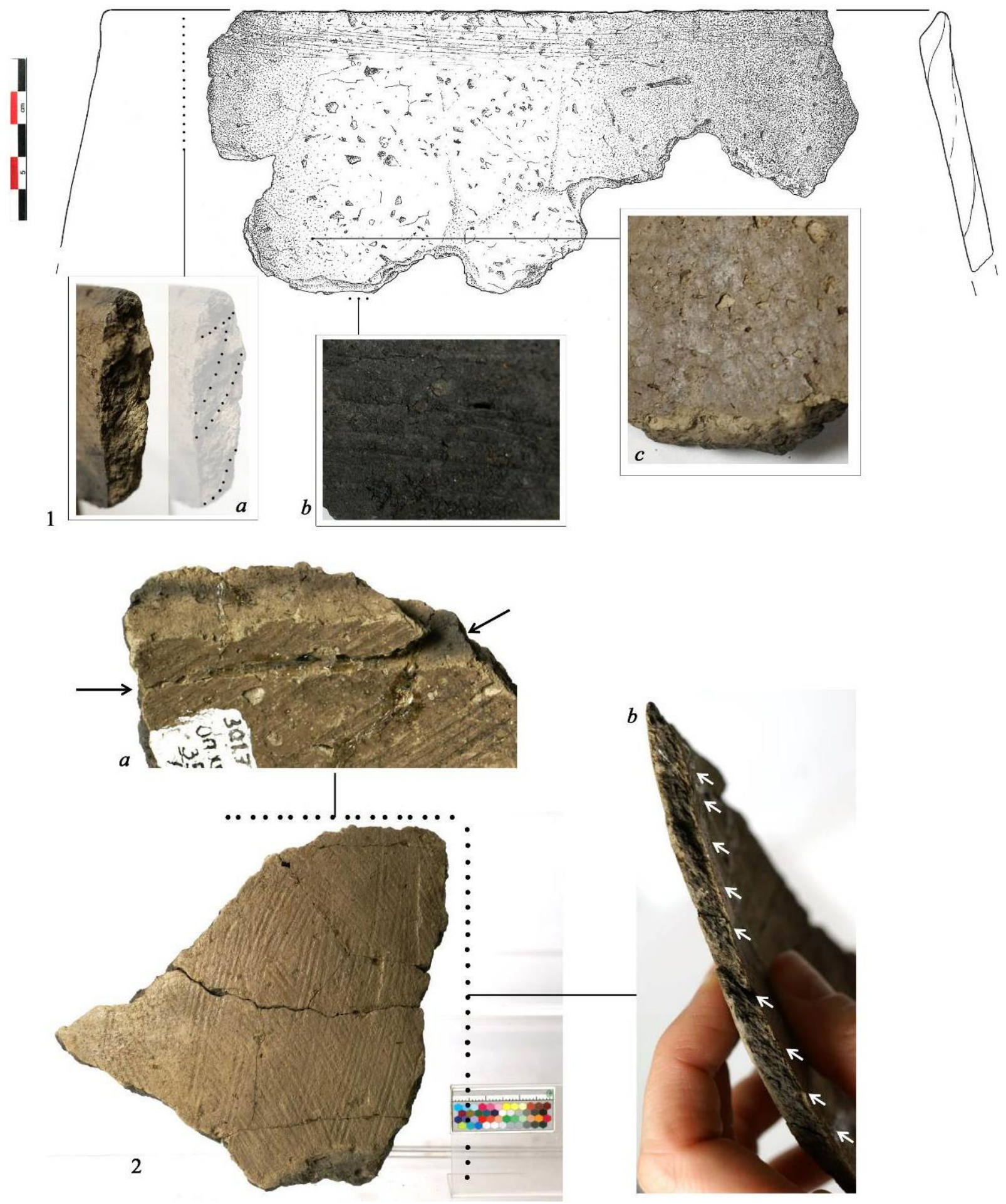

Рисунок 4 - Фрагменты глиняных сосудов фазы «d-1»

(1- п. Рудня Сертейская; 2- п. Сертея XIV) с указанием следов, оставленных при обработке внешней (1c) и внутренней поверхности $(1 b)$, и мест стыковки лент (1a, 2a-b)

К сожалению, пока открыт только один памятник - Рудня Сертейская - по материалам которого можно судить о кремневой и костяной индустрии сопровождающей в целом находки керамики фаз «d» и «d1» [2, рис. 5-7]. Среди кремневых орудий можно выделить наконечник стрелы ромбовидной формы с двусторонней обработкой, концевой скребок, скребки на отщепах округлой формы и округлым лезвием, топоры овальной формы с ассиметричным линзовидным сечением и с сохранившимися на лезвии шлифованными участками. Нуклеусы представлены двумя одноплощадочными торцевыми и двумя двуплощадочными. Наконечники из кости и рога пред- ставлены тремя игловидными, биконическим наконечником с игловидным насадом, биконическим уплощенным наконечником с симметричными шипами и игловидным насадом (еще один такой экземпляр найден на п. Сертея II), наконечником с конически-овальным орнаментированным пером с овальной нарезкой посредине и с длинным игловидным насадом, наконечником остроги с тремя зубцами и лопатковидным насадом, кинжалом из локтевой кости лося, острия. К этому комплексу относится и находка наконечника из сосны с конусообразным пером, цилиндрическим туловом и плоским зауженным к концу насадом. 

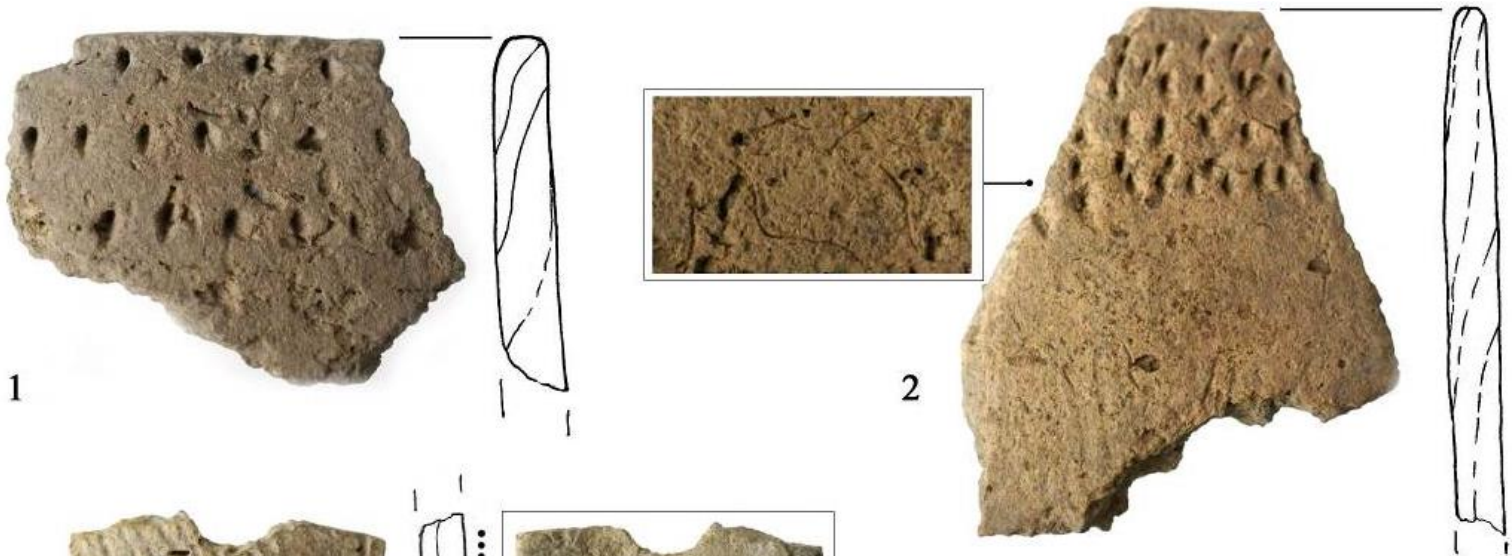

3
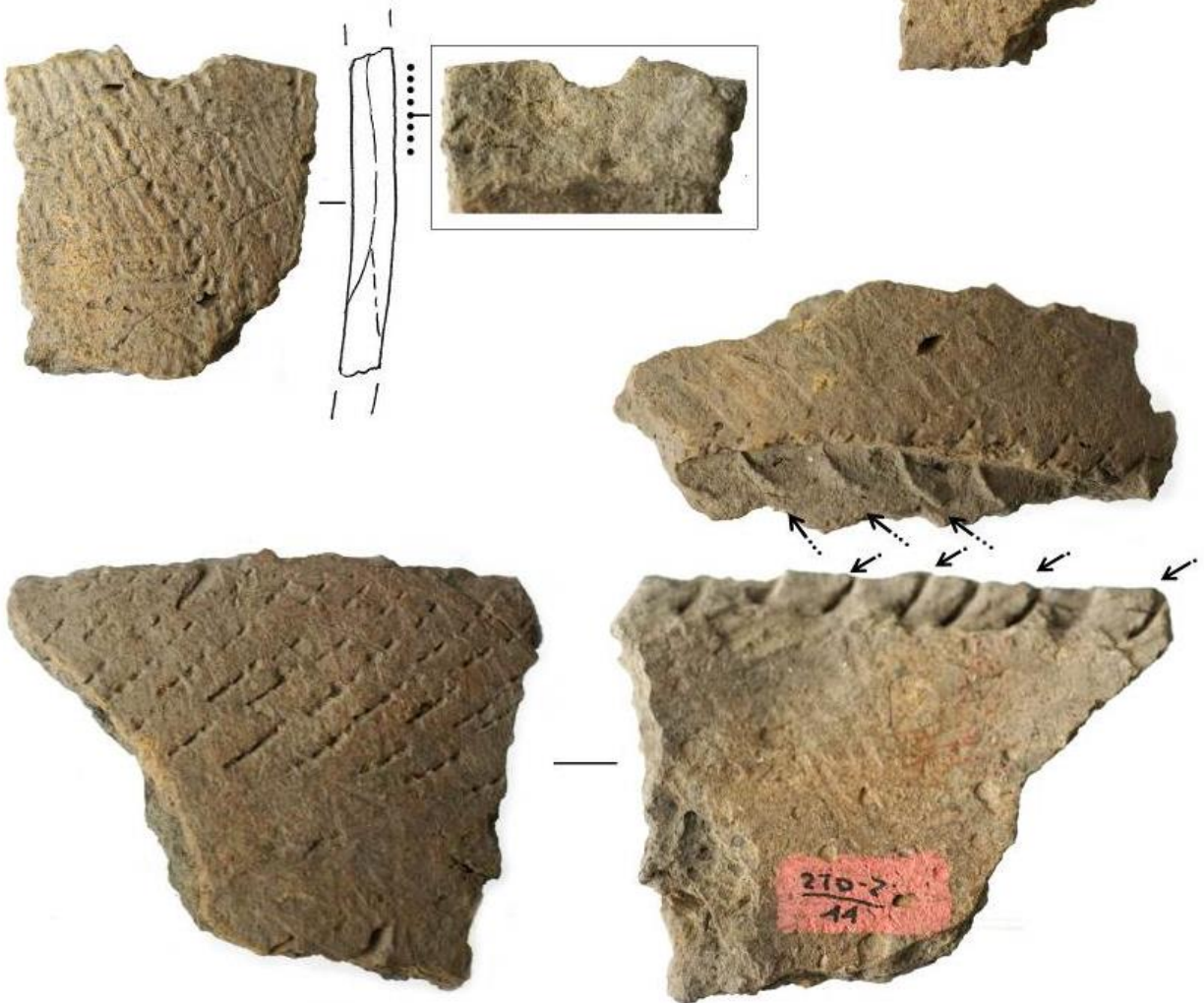

Рисунок 5 - Фрагменты глиняных сосудов фазы «е» (1-4- п. Узмень)

Анализ пространственного распределения находок руднянской керамики позволяет выделить на памятниках остатки конструкций. На памятниках Cертея X и XIV зафиксированы остатки построек кольевой конструкции подпрямоугольной или округлой формы с наземными очагами [5].

Для керамики фаз «d» $u$ «е» можно усмотреть определенные аналогии в посуде памятников Лубанской котоловины: Звидзе, Оса [6; 7]. Для керамики фазы «d-1» аналогии просматриваются также в отдельных типах керамики п. Звидзе и памятников на территории Эстонии [8; 9] (рис. 6).

Важно отметить, что кремневый комплекс не аналогичен материалам более раннего времени, а предметы из рога и кости хоть и имеют сходство с позднемезолитическими - ранненеолитическими материалами памятников лесной зоны Восточной Европы, наиболее точные, морфологические, аналогии имеют в коллекциях памятников из Лубанской котловины $[6 ; 10]$.

Хронология руднянской культурь

Стратиграфические наблюдения показывают, что культурные слои с материалами руднянской археологической культуры залегают над слоями с материалами керамических фаз «a- $1 »-\langle b-5 »$, в т.ч. и сертейской археологической культуры. Данное наблю- дение важно для установления относительной хронологии древностей. Абсолютная хронология материалов фазы «d» устанавливается по фрагментам обработанной древесины (6240 440 BP (Le-3054) (53115066 cal BC), 6230 \pm 40 BP (Le-2568) (5306-5061 cal BC),6180 \pm 40 BP (Le-2569) (5286-5002 cal BC), $6130 \pm 40$ BP (Le-2579) (5211-4962 cal BC)), залегавшей в непосредственной близости и на одном уровне с керамикой на стоянке Рудня Сертейская [2; 3]. Было получено семь дат, образующих две совокупности. Эти две группы радиоуглеродных дат скорее всего отражают несколько этапов посещения данного места в рассматриваемый период. В пользу данного предположения, о кратковременности и сезонности пребывания на этом месте древнего населения, говорят фаунистические находки птиц [11, табл. 1].

Еще одна серия радиоуглеродных датировок была получена на памятнике Сертея XIV [3, табл. 1]. Здесь датировки образуют несколько группы. Даты из остатков овальной наземной постройки несколько древнее датировок керамики фазы «d» со стоянки Рудня Сертейская. Две датировки $5850 \pm 280 \mathrm{BP}$ (Le 4100) (5463-4076 cal BC) и 5890 \pm 60 BP (Le -2586) (4932-4608 cal BC), показывающие время накопления во время небольшой трансгрессии сапропеля над культурными остатками слоя В ст. Рудня Сертей- 
Мазуркевич А.Н., Долбунова Е.В. 07.00.00 - исторические науки и археология Древности конца VI - первой половины V тыс. до н.э. в Верхнем Подвиньи ская, говорят о времени существования стоянок на рекрывающего находки с материалами $\phi a з ~ « d » ~ и ~ « d-$ минеральном берегу с материалами фазы «е». Вторая группа дат синхронна датировкам рыболовного сооружения со стоянки Рудня Сертейская из слоя пе-

1», что позволяет предположить верхнюю границу существования древностей фазы «е» около $5780 \pm 50$ BP (Le -2577) (4766-4499 cal BC).
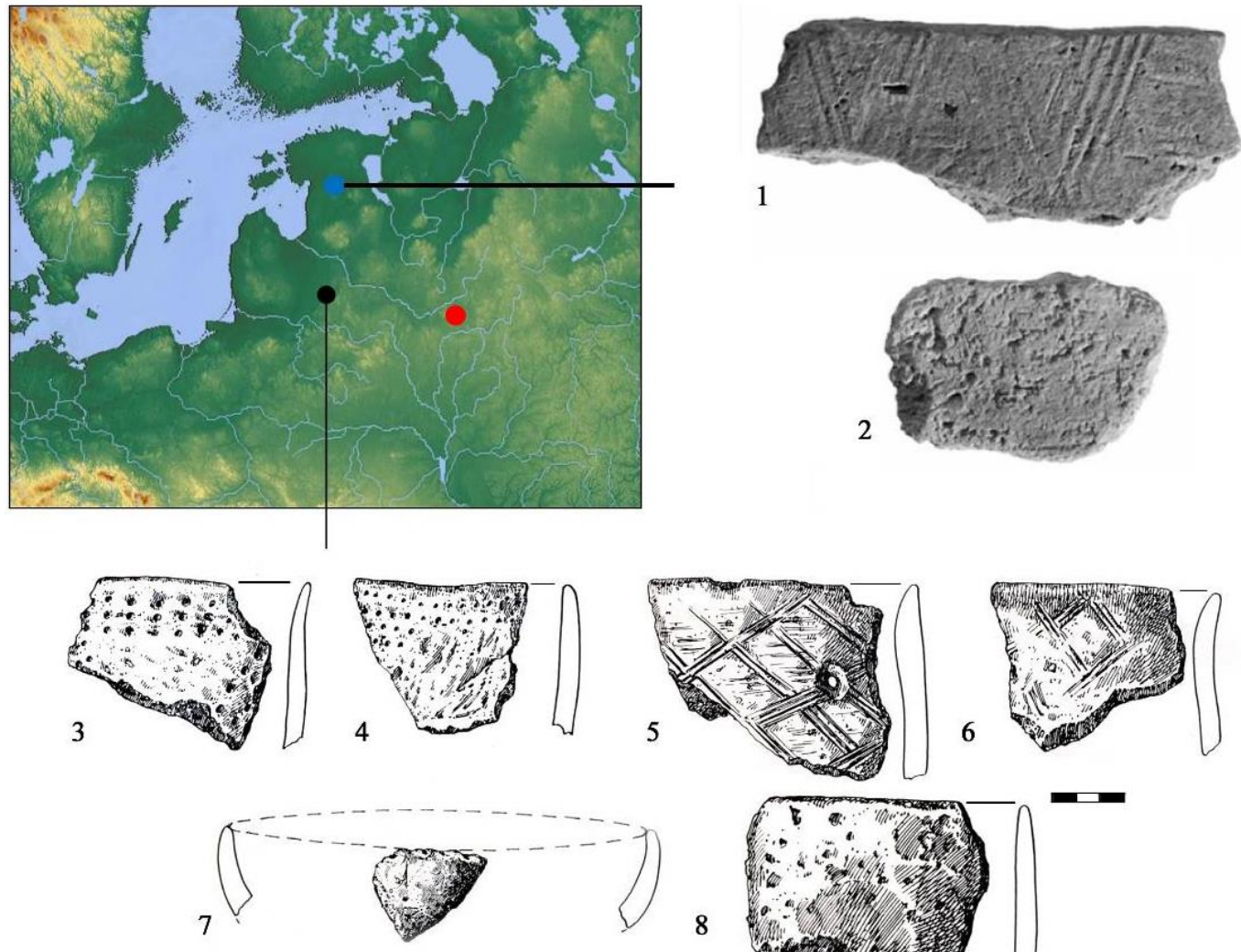

8

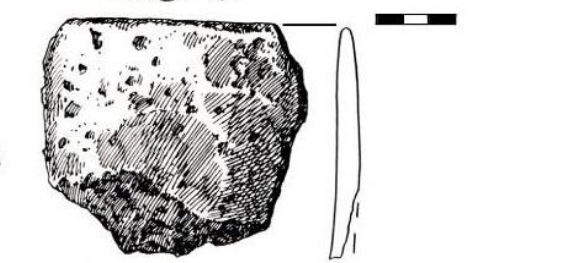

Рисунок 6 - Глиняная посуда нарвской культуры с территории Эстонии ( $1-$ п. Narva Joaorg 2; 4- п. Vihasoo III [9]) и Латвии (3-8- п. Звидзе [6])

\section{Дискуссия}

Достаточно специфические черты отдельных фаз - технологические, морфологические и орнаментальные - не позволяют рассматривать их как монолитное культурное явление, а как состоящее из различных элементов. Для рассматриваемого хронологического эпизода последней четверти 6 - начала 5 тыс. до н.э. мы можем зафиксировать наличие по особенностям керамического производства как минимум двух культурных комплексов, соответствующих руднянской археологической культуре (фаза «d» и «е») и материалы $\phi a з ы ~ « d-1 »$. Такое явление встречается в Лубанской котловине и Эртебелле. Многие исследователи рассматривают это как проявление мультикультурализма. [12]

При сравнении с комплексами нарвской культуры, согласно описанию Н.Н. Гуриной [1967], можно сказать, что керамика руднянской культуры отличается по набору технологических, морфологических, орнаментальных признаков. В работах исследователей ранее неоднократно подчеркивалось, что на предполагаемой территории распространения нарвских памятников выделяются локальные и локальнохронологические варианты со своими особенностями [8-10; 13-16]. Таким образом, руднянская культура может представлять самостоятельное культурное явление в рамках одной большой культурной общности [17]. При этом наиболее близкие аналогии как керамическому комплексу, так и предметам из кости и рога мы находим в материалах нижнего течения p. Западная Двина в Лубанской котловине, откуда и мог исходить культурный импульс, приведший к появлению на рассматриваемой территории руднянской археологической культуры.

Представленные аналогии руднянской культуре указывают на смену векторов культурных взаимодействий в конце 6 тыс. до н.э., что является маркером разрушения сложившейся сети культурных связей, существовавшей до этого на протяжении 76 тыс. до н.э. [2; 4; 17]. Кроме этого, мы должны отметить кардинальную смену материальной культуры и практически полное отсутствие связей с предшествующими древностями на данной территории. По всей видимости, что древности данного типа распространяются в восточном направлении во второй половине 6 тыс. до н.э. из Восточной Прибалтики. Столь кардинальную смену материальной культуры можно рассматривать как результат проявления значительного не только культурного импульса, но появления нового населения с западных территорий, которые, вероятно, и устанавливают новую систему культурных, социальный связей.

Сравнение технологических и морфологических признаков комплекса глиняной посуда руднянской, нарвской и памятников типа Струмель [18], Эртебелле [12] показывает лишь их внешнее сходство (например, наличие общих признаков: оттянутые/шиповидные донца), это лишь сходная манера оформления сосудов и их отдельных частей. Что и какое культурное явление стоит за выявленным в свое время В.И. Тимофеевым [19] культурным феноменом, нам еще предстоит разобраться [20]. 


\section{СПИСОК ЛИТЕРАТУРЫ:}

1. Dolukhanov P.M., Gey N.A., Miklyayev A.M., Mazurkiewicz A.N. Rudnya-Serteya, a stratified dwelling-site in the upper Duna basin (a multidisciplinary research) // Fennoscandia archaeological. 1989. Vol. VI. P. 23-27.

2. Мазуркевич А.Н., Микляев А.М. О раннем неолите междуречья Ловати и Западной Двины // Археологический сборник Государственного Эрмитажа. № 33 / под ред. Б.Б. Пиотровского. СПб.: Государственный Эрмитаж, 1998. С. 7-31.

3. Мазуркевич А.Н., Зайцева Г.И., Кулькова М.А., Долбунова Е.В., Семенцов А.А., Ришко С.А. Абсолютная хронология неолитических древностей Днепро-Двинского междуречья VII-III тыс. до н.э. // Paдиоуглеродная хронология эпохи неолита Восточной Европы в VII-III тыс. до н.э. / ред. А.Н. Мазуркевич, М.А. Кулькова, Е.В. Долбунова. СПб., 2016. С. 310345.

4. Мазуркевич А.Н., Долбунова Е.В., Кулькова М.А. Древнейшие керамические традиции Восточной Европы // Российский археологический ежегодник. 2013. № 3. C. 27-108.

5. Мазуркевич А.Н., Кулькова М.А., Полковникова М.Э., Савельева Л.А. Ранненеолитические памятники Ловатско-Двинского междуречья // Неолитэнеолит юга и неолит севера Восточной Европы / науч. ред. В.И. Тимофеев. СПб., 2003. С. 260-268.

6. Лозе И.Л. Поселения каменного века Лубанской низины: мезолит, ранний и средний неолит. Рига: Зинатне, 1988. 209 с.

7. Zagorskis F. Agrais neolita laikmets Latvijas austrumdala // Latvijas PSR Zinatnu Akademijas Vestis. 1973. № 4. P. 56-69.

8. Kriiska A. The neolithic pottery manufacturing technique of the lower course of the Narva River // Coastal Estonia. Recent Advances in Environmental and Cultural History. PACT 51. Rixensart, 1996. P. 373-384.

9. Kriiska A., Oras E., Lougas L., Meadows J., Lucquin A., Craig O. Late Mesolithic Narva stage on the territory of Estonia: pottery, settlement types and chronology // Estonian Journal of Archaeology. 2017.

10. Ванкина Л.В., Загорскис Ф.А., Лозе И.А. Неолитические племена Латвии // Этнокультурные обла- сти лесной и лесостепной зоны европейской части СССР в эпоху неолита. МИА № 172. 1973.

11. Саблин М.В., Пантелеев А.В., Сыромятникова Е.В. Археозоологический анализ остеологического материала из неолитических свайных поселений Подвинья: хозяйство и экология // Труды зоологического института РАН. 2011. Т. 315, № 2. С. 143-153.

12. Глыкой А. Керамика Эртебёлле: распостранение, типология, технология и хронология // Культурные процессы в Циркумбалтийском пространстве в раннем и среднем голоцене / отв. ред. Д.В. Герасимов. СПб.: Издательство «Лема», 2017. С. 268-272.

13. Римантене Р.К. Неолит Литвы и Калининградской области // Этнокультурные области лесной и лесостепной зоны европейской части СССР в эпоху неолита. МИА. 1973. № 172.

14. Тимофеев В.И. К вопросу о временных различиях некоторых памятников раннего неолита Восточной Прибалтики // Краткие сообщения Института археологии. 1975. Вып. 141.

15. Miksaite S. Production of ceramics of Narva culture (reconstructions based on experimental archaeology) // Estonian Journal of Archaeology. 2005. Vol. 9, is. 1. P. $60-72$.

16. Piezonka H. Jäger, Fischer, Töpfer. Wildbeuter mit früher Keramik in Nordosteuropa im 6. und 5. Jahrtausend v. Chr. Archäologie in Eurasien 30. Bonn. 2015.

17. Мазуркевич А.Н. О раннем неолите ЛоватскоДвинского междуречья // Петербургский археологический вестник. 1995. № 9. С. 77-84.

18. Ногин Е.В. Материалы памятников струмельского типа на территории Украины // Культурные процессы в Циркумбалтийском пространстве в раннем и среднем голоцене / отв. ред. Д.В. Герасимов. СПб.: Издательство «Лема», 2017. С. 264-267.

19. Тимофеев В.И. Некоторые проблемы неолитизации Восточной Европы // Тверской археологический сборник. Вып. 5. Тверь, 2002. С. 209-214.

20. Гурина Н.Н. Из истории древних племен западных областей СССР. МИА № 144. 1967.

\section{MATERIAL CULTURE OF THE END OF THE VI MILL. - FIRST HALF OF THE V MILL. BC IN THE UPPER WESTERN DVINA RIVER BASIN}

(C) 2017

Mazurkevich Andrey Nicolaevich, senior researcher, general curator of Eastern Europe and Siberia Archaeology Department Dolbunova Ecaterina Vladimirovna, candidate of historical sciences, junior researcher of Eastern Europe and Siberia Archaeology Department State Hermitage Museum (Saint Petersburg, Russian Federation)

Abstract. Rudnyanskaya culture was distinguished based on materials found on a stratified site Rudnya Serteyskaya (NW Russia, serteysky archaeological microregion) in 1983-1987. It existed from the end of the VI mill BC to the beginning of the V mill BC, after ceasing of the first Neolithic ceramic traditions in Dnepr-Dvina region. Pottery assemblage was divided into three ceramic phases $d, d-1$ and $e$. They cannot be regarded as one single cultural phenomenon due to differences in technology, morphology and decor of vessels. Analogies in pottery, flint and bone assemblage can be traced within the sites of Lubana region (Zvidze, Osa). We might suppose that vectors of cultural interactions changed at the end of the VI mill BC, and a former cultural network was destroyed. However rudnyanskaya culture differs a lot from Narva culture described by N.N. Gurina due to technological, morphological and decor characteristics. Local and local-chronological variants were distinguished on the territory of Narva culture distribution. Rudnyanskaya culture can be supposed to be one of these cultural phenomenons existed within a large common cultural area.

Keywords: Neolithic; neolithisation; early Neolithic; forest zone of Eastern Europe; Upper Dvina basin; Narva culture; Rudnya culture; Ertebelle; sites of Strumel type; pottery technology; radiocarbon chronology; cultural traditions. 